Letrônica, Porto Alegre, v. 7, n. 2, p. 934-948, jul./dez., 2014

\title{
A VIAGEM E O INDIVÍDUO EXILADO: UMA LEITURA APROXIMATIVA ENTRE LUÍS DE CAMÕES E ANTÓNIO LOBO ANTUNES
}

\author{
THE TRAVEL AND THE EXILED MAN: \\ AN APPROXIMATE READING BETWEEN LUÍS DE CAMÕES AND \\ ANTÓNIO LOBO ANTUNES
}

Mariana Andrade da Cruz*

\begin{abstract}
Resumo: No presente trabalho, pretendemos analisar o romance Sôbolos rios que vão, de António Lobo Antunes, cujo título é inspirado no poema homônimo de Luís de Camões. Cremos que seja possível vislumbrar, tanto no eu-lírico camoniano quanto no protagonista antuniano, a representação de indivíduos exilados, que se deparam, no presente, com um lugar estrangeiro. Inspirados pela leitura do poema de Camões, desejamos observar como se dá, na obra contemporânea, a oposição entre saúde e doença, infância e maturidade, tempo anterior e tempo presente.
\end{abstract}

Palavras-chave: António Lobo Antunes; Luís de Camões; Sôbolos rios que vão.

Abstract: In this paper, we analyze the novel Sôbolos rios que vão, written by António Lobo Antunes. The novel's title is inspired in a poem by Luís de Camões. We compare the representation of exiled men faced, at present, with a foreign place in these texts. Based on the reading of the poem, we perceive, in the novel, the oppositions between health and disease, childhood and maturity, previous time and current time.

Keywords: António Lobo Antunes; Luís de Camões; Sôbolos rios que vão.

Sôbolos rios que vão Por Babilónia, m'achei

E ali sentado chorei

As lembranças de Sião

E quanto nela passei.

Luís Vaz de Camões (2002, p. 66)

Seria quase impossível iniciarmos o presente artigo com outra epígrafe que não fosse a estrofe primeira deste famoso poema camoniano, cujo verso de abertura serve de

\footnotetext{
* Doutoranda em Literatura Comparada pela Universidade Federal Fluminense - UFF. Bolsista do Conselho Nacional de Desenvolvimento Científico e Tecnológico - CNPq. Orientanda da Professora Doutora Dalva Calvão, e vinculada ao projeto de pesquisa desta, a saber: "Do barroco ao neobarroco: configurações da ficção portuguesa contemporânea".
} 
título a um poema quinhentista e a um romance do século XXI, que aqui pretendemos analisar. As apresentações são dispensáveis: de um lado, temos o expoente máximo das literaturas lusófonas, figura imprescindível não só na literatura como no imaginário cultural português e ibérico, poeta cujas obras foram emuladas, parafraseadas e mencionadas incontáveis vezes desde o século XVI: este é Luís de Camões. De outro lado, temos um romancista contemporâneo, galardoado com a premiação maior para autores de língua portuguesa - justamente o prêmio Camões -, produzindo textos desde o final da década de 70 e autor de quase trinta livros de ficção, afora variadas crônicas: este é António Lobo Antunes. Curiosamente, o primeiro já foi personagem do último, no cáustico e irônico romance As naus, que parodia as grandes navegações de Portugal. Situar biograficamente tais autores ou falar sobre a relevância de estudá-los seria, portanto, dispensável. Apesar disso, desejamos falar brevemente sobre Lobo Antunes e as características de seu fazer literário, como forma de sedimentar bases para a análise intertextual e literária que faremos em sequência.

António Lobo Antunes não é um escritor conhecido exatamente por sua modéstia. Ao contrário: proclama, alto e bom som, nas pontuais entrevistas que concede, que é o maior nome da literatura portuguesa em atividade. Definitivamente, ao pontuar esse tipo de colocações, o autor não está desejando angariar simpatias relacionadas a sua pessoa. Mas mesmo aqueles que rechaçam a figura pública Lobo Antunes têm de dar o braço a torcer diante de sua obra: o vencedor do prêmio Camões tem uma obra consistente, está há muito estabelecido no cânone literário, é um dos autores contemporâneos portugueses mais lidos e publicados em outros países e é uma referência para muitos estudiosos e acadêmicos - e sabe disso. Suas empreitadas são tão ousadas quanto o volume e a densidade das páginas de muitos de seus romances.

A ficção de António Lobo Antunes sempre se prodigalizou por determinadas características marcantes, as quais, por sua recorrência, compõem uma fortuna literária peculiar, na esteira da rica produção portuguesa contemporânea em prosa. As repetições de propostas de ordem temática e estilística auxiliam-nos, inclusive, na categorização de certas fases no percurso literário do escritor, tais como a trilogia de Benfica, formada por Tratado das paixões da alma, A ordem natural das coisas e A morte de Carlos Gardel, ou ainda a tetralogia do poder, formada por $O$ manual dos inquisidores, O esplendor de Portugal, Exortação aos crocodilos e Boa tarde às coisas aqui em baixo. 
Baseada talvez na predileção do autor por certo excesso, em volume de páginas e também na densidade de suas narrativas polifônicas - embora todas as personagens estejam notadamente marcadas pelo signo da falta, tema ao qual aludiremos mais adiante -, Clara Ferreira Alves enquadra Lobo Antunes em sete pecados capitais, assim listados e comentados por Ana Paula Arnaut:

Não por acaso, portanto, surge como consensual a ideia de que a escrita de António Lobo Antunes prima pelo gosto em complicar canônicas noções como narrativa, tempo, espaço, personagens, etc. Uma complexidade que, num passado já distante, o levou a ser acusado de ter cometido sete (literários) pecados mortais. Contam-se, entre eles (numa paleta que abrange ainda a excessiva "acumulação de comparações", "as imagens", "o mau gosto", o "excesso a todos os níveis" e a "referência cinematográfica"), "a imperfeita interligação da ação e digressão" ou "[]a técnica da narração", isto é, aspectos decorrentes da crescente proliferação de vozes nos universos antunianos e, por consequência, da instauração de diversos sentidos (aparentemente) desviados e desviantes. (ARNAUT, 2008, p. xxii)

Conquanto todas as características acima listadas sejam de fato marcantes porém não pecados, no sentido pejorativo do termo, visto que suas técnicas narrativas levam-nos, leitores, à leitura de fruição e ao constante hábito de levantar a cabeça, para utilizar a expressão barthesiana -, desejamos aqui destacar, de forma breve, dois outros pontos que brotam de suas páginas, com especial ênfase em sua produção ficcional mais recente.

0 primeiro ponto é o possível retorno do autor ao registro parcialmente autobiográfico, com personagens que podem ser vistas como personae do ficcionista. A característica é reconhecidamente aceita pelos estudiosos da obra antuniana, que veem em seus três primeiros romances - respectivamente Memória de elefante, Os cus de Judas e Conhecimento do inferno - correspondências entre a vida civil do indivíduo António Lobo Antunes - de formação psiquiátrica, médico do exército por vinte e sete meses durante a guerra colonial em Angola e depois residente no hospital psiquiátrico Miguel Bombarda, em Lisboa - e o protagonista de seus romances iniciáticos. 0 primeiro momento de sua escrita é reconhecido como a fase da aprendizagem, uma vez que ainda estavam por ser amadurecidos técnicas e procedimentos refinados em obras posteriores. Nestes romances, por exemplo, ainda não havia a teia polifônica, traço marcante do autor, que surgiria a partir de Explicação dos pássaros.

Parece-nos que os romances mais recentes do autor têm se voltado para a sua incursão gradativa no universo textual - como ocorre, por exemplo, em Que cavalos são 
aqueles que fazem sombra no mar?, em um momento em que o romancista revela-se enquanto entidade consciente de seu papel autoral e, em diálogo (simulado?) com a personagem, dirige-se para a função metalinguística da linguagem ("o António Lobo Antunes / - Escrevo assim? / e eu / - Escreva" (ANTUNES, 2011, p. 140). No entanto, aqui pensamos em um novo plano na ficção antuniana, similar ao ponto inicial, em que o autor, ainda que enquanto persona, volta a sugestivamente ocupar - ou a parecer ocupar - as páginas de sua obra. Pensamos especificamente em Sôbolos rios que vão e em seu protagonista enfermo, vivendo o pós-operatório e o tratamento de um tumor maligno durante os meses de março e abril de 2007 - o romance vem a público em 2010. Lembramos que António Lobo Antunes foi igualmente vítima de tal doença e submeteuse a tratamento aproximadamente no mesmo período que sua personagem. Entretanto, a inevitável aproximação consolida-se quando lemos, em várias partes do romance, que a personagem era, na infância, chamada de Antoninho; e que, na fase adulta, é conhecido como senhor Antunes.

\footnotetext{
calava-se, a dona Irene apertou-lhe um algodão contra o braço e as mil canetas do notário brilhavam

- Antoninho

a dona Irene a levantar-se

- Não o magoei amigo? (SRV, p. 12)i

- Está com melhor aspecto hoje

Como se atreviam a afirmar que melhor aspecto se ignoravam quem ele era, o pingo no sapato

- Senhor Antunes

Enganado no nome, acabou-se o Antunes, qual o meu apelido, por que razão aqui estou, não se sentia doente, apenas lhe custava que apagassem as luzes (SRV, p. 116).
}

A outra característica da produção ficcional de António Lobo Antunes que desejamos realçar são as referências constantes, explicitamente presentes nos títulos de muitas de suas obras, a outros textos literários - notadamente a versos de poemas. É o que vemos, por exemplo, em Que farei quando tudo arde?, verso extraído de belo texto de Sá de Miranda; Ontem não te vi em Babilónia, frase encontrada pelo autor em poema do cubano Eliseo Diego (e lida no original, em espanhol); e em seu último romance, Não é meia noite quem quer, citação cuja origem está na poesia do francês René Char. Talvez o desejo de dialogar com poetas seja a resposta a uma certa ambição por ser poeta, que o autor já revelou em diversas entrevistas, como por exemplo aquela concedida a 
Alexandra Lucas Coelho, em janeiro de 2000, quando afirma categoricamente: "As minhas pobres tentativas poéticas davam-me muito mais prazer que o romance. Mas é preciso ter-se nascido para isso" (lido em ARNAULT, 2008, p. 530). Em passagem relativamente recente pelo Brasil, Lobo Antunes reiterou seus comentários acerca da apreciação do estilo poético e de sua frustração por ser um poeta inviável em palestra ministrada no Real Gabinete Português de Leitura.

Em Sôbolos rios que vão, o diálogo evidente é com aquele poeta que é consensualmente considerado o maior nome das literaturas lusófonas. Ao manter a grafia antiga sôbolos, Lobo Antunes explicita a ligação com o famoso verso inicial do texto de Luís de Camões, este inspirado em salmo bíblico acerca do exílio do povo judeu em Babilônia. Texto exemplar, acerca do poema de Camões, nas palavras de Cleonice Berardinelli, "ninguém hesitaria em afirmar que a 'medida velha' o encontra [o ponto alto]" (2000, p. 39). Como falar do poema sem efetivamente lê-lo poderia soar como incompletude, iremos, sem mais delongas, aos versos camonianos. Em razão da relativa extensão da obra, selecionamos, aqui, algumas estrofes, dispostas de modo a transmitir, ainda que superficialmente, o percurso do poema: estão aqui as estrofes iniciais e finais, bem como algumas presentes no decorrer do texto:

\footnotetext{
Sôbolos rios que vão por Babilónia, m’achei, Onde sentado chorei as lembranças de Sião e quanto nela passei. Ali, o rio corrente de meus olhos foi manado, e, tudo bem comparado, Babilónia ao mal presente, Sião ao tempo passado.

Ali, lembranças contentes n'alma se representaram, e minhas cousas ausentes se fizeram tão presentes como se nunca passaram. Ali, depois de acordado, co' rosto banhado em água, deste sonho imaginado, vi que todo o bem passado não é gosto, mas é mágoa.

E vi que todos os danos se causavam das mudanças e as mudanças dos anos;
} 
onde vi quantos enganos

faz o tempo às esperanças.

Ali vi o maior bem

quão pouco espaço que dura,

o mal quão depressa vem,

e quão triste estado tem

quem se fia da ventura.

Vi aquilo que mais val, que então se entende milhor quanto mais perdido for; vi o bem suceder o mal, e o mal, muito pior,

E vi com muito trabalho comprar arrependimento; vi nenhum contentamento, e vejo-me a mim, que espalho tristes palavras ao vento.

(..)

Mas lembranças da afeição que ali cativo me tinha, me perguntaram então: que era da música minha que eu cantava em Sião? Que foi daquele cantar das gentes tão celebrado? Porque o deixava de usar? Pois sempre ajuda a passar qualquer trabalho passado.

Canta o caminhante ledo no caminho trabalhoso, por entre o espesso arvoredo; e, de noite, o temeroso, cantando, refreia o medo. Canta o preso docemente os duros grilhões tocando; canta o segador contente; e o trabalhador, cantando, o trabalho menos sente.

$\mathrm{Eu}$, que estas cousas senti n'alma, de mágoas tão cheia, - Como dirá, respondi, quem alheio está de si doce canto em terra alheia? Como poderá cantar quem em choro banha o peito? Porque, se quem trabalhar canta por menos cansar, eu, só, descansos enjeito.

Que não parece razão nem seria cousa idónea, por abrandar a paixão, que cantasse em Babilónia 
as cantigas de Sião.

Que, quando a muita graveza

de saudade quebrante

esta vital fortaleza,

antes moura de tristeza

que, por abrandá-la, cante.

Que se o fino pensamento

só na tristeza consiste, não tenho medo ao tormento:

que morrer de puro triste,

que maior contentamento?

Nem na frauta cantarei

o que passo, e passei já,

nem menos o escreverei,

porque a pena cansará,

e eu não descansarei.

Que, se a vida tão pequena

se acrescenta em terra estranha, e se amor assi o ordena, razão é que canse a pena de escrever pena tamanha. Porém se, para assentar o que sente o coração, a pena já me cansar, não canse para voar a memória em Sião.

\section{(...)}

Quem do vil contentamento cá deste mundo visível, quanto ao homem for possível, passar logo o entendimento para o mundo inteligível: ali achará alegria em tudo perfeita e cheia de tão suave harmonia, que, nem por pouca, recreia, nem, por sobeja, enfastia.

Ali verá tão profundo mistério na suma Alteza, que, vencida a natureza, os mores faustos do mundo julgue por maior baixeza. Ó tu, divino aposento, minha pátria singular! Se só com te imaginar tanto sobe o entendimento, que fará se em ti se achar?

Ditoso quem se partir para ti, terra excelente, tão justo e tão penitente que, depois de a ti subir lá descanse eternamente. (2002, p. 66 - 76). 
As estrofes acima transcritas já permitem a demarcação de certos pontos temáticos bastante caros à produção lírica - e que também transparece, em variados momentos, na épica - de Camões. Poderíamos elencar aqui, a título de exemplo, o sintomático jogo com a polissemia da palavra pena - fartamente explorada na glosa a partir do famoso mote "Perdigão perdeu a pena / Não há mal que lhe não venha" e que indicia a reflexão acerca da prática literária usualmente empreendida por Camões, inclusive nas estrofes finais d'Os Lusíadas, frequentemente lembradas por seu traço metalinguístico. Entretanto, chamam-nos a atenção, também, duas características em especial, que destacaremos e sobre as quais nos debruçaremos a seguir.

A primeira dessas características seria o jogo de contrastes explícito em pares opositores tais como ali/aqui, cantar/ chorar, tristeza/contentamento. A outra característica, ligada à primeira e em certo sentido mãe dela, é o tom maneirista/barroco presente na voz desse eu-lírico que, ao comparar opostos, percebe o quanto o mundo é desconcertado, e, mediante essa angulação, lamenta a sua condição atual, vítima da mudança e subjugado pelo degredo. Assim coloca António José Saraiva tal questão: “a 'mudança' traz o homem 'de esperança em esperança, e de desejo em desejo'. Mas quem gozou alguma vez uma felicidade presente? Onde existe uma felicidade que não seja meramente uma lembrança de um passado?” (1950, p. 315).

Torna-se interessante lembrar, aqui, que, dentro dos grandes temas barrocos, encontraremos também a ideia do mundo como estalagem: lugar de passagem, não estabelecido, temporário, onde, a despeito de qualquer conforto vivenciado, seria impossível sentir-se plenamente habituado - ou em casa, para utilizar uma expressão bastante popular. A partir de tal concepção, ocuparia o homem o papel de peregrino: ele "se vê posto no mundo, tendo de haver-se com ele e tendo, ao mesmo tempo, de conseguir fazer do mundo um suporte seguro em que se apoiar" (MARAVALL, 1997, p. 257); resta ao indivíduo acostumar-se a esse mundo adverso, não obstante a permanente sensação de não pertencimento pleno àquele local. Sem que entremos aqui nas questões teóricas que propõem as similitudes e as diferenciações entre maneirismo e barroco, e considerando a concepção dada por Jorge de Sena em estudo efetuado acerca das marcas daquele movimento em Camões - a de que "no vácuo aberto entre o medievalismo que vem morrer no Renascimento, e a idade moderna que nascerá, oculta, 
nas vascas curvilineamente geométricas do Barroco, o maneirismo é uma angustiada liberdade" (1980, p. 53) -, o pensamento camoniano transmite-nos certa sensação de mundo que se encontra muito próxima a um perfil marcado pelo maneirismo, com possível recaimento em uma visão barroca. Afinal, versos sobre as dubiedades e imprevisibilidades do destino - ou da fortuna, para usar a nomenclatura frequentemente adotada pelo poeta -, bem como sobre a efemeridade da vida humana, não são tão incomuns na produção lírica daquele que, em certo soneto, declarou que "mudam-se os tempos, mudam-se as vontades" (2002, p. 102).

Nessas duas características residem alguns pontos de contato entre o poema camoniano e o romance antuniano. Para o narrador de Sôbolos rios que vão, também há oposições, sobretudo baseadas nos pares saúde/doença e infância/maturidade, sistematização em que o período da inocência equivale a uma felicidade então desconhecida e só na maturidade entendida - inevitavelmente lembramo-nos dos versos de Fernando Pessoa: “Eu era feliz? Não o sei, / Fui-o outrora agora.” (s.d., p. 70). Em contraponto, a vida adulta presente traz consigo a insegurança e o fim das ilusões desse indivíduo atormentado não só pela doença, como também por certa angústia existencial trazida pela enfermidade - mas não devida apenas a ela. 0 deslocamento de um lugar seguro e estabelecido para o permanente passo em falso do ambiente hospitalar submete a personagem a contínuos momentos reflexivos nos quais a dicotomia entre ontem e hoje é constantemente evocada, a exemplo do trecho a seguir, no qual a repetição anafórica da conjunção "e" frisa, a princípio, a ironia do discurso do adoentado, e, logo a seguir, a recuperação das imagens do passado:

\footnotetext{
- Há-de correr tudo bem senhor Antunes

e claro que há-de correr tudo bem amigo embora os cães me levem pedaço a pedaço, já corre tudo bem não vê, o coração e o fígado hesitam mas começam de novo, a dor fareja se me distraio mas não aborrece, desiste, é janeiro amigo, não março, os candeeiros acesos às quatro da tarde e em redor dos candeeiros a noite, o pingo no sapato a devolver-lhe o ombro

- Ao contrário do que possa pensar não estou desiludido

e graças a Deus que nenhum de nós se desilude amigo, não é outubro como na vila e a água não assobia nos ossos da minha avó nem a hera começa a perder as gavinhas, os lobos abandonam a escola e eu no hospital sem sentir o corpo vazio, como você disse a olhar para outro lado não para mim

- Hoje em dia temos mais recursos

e temos a camioneta da carreira e o poço, a gente debruça-se e nem um brilho no lodo, um contorno de pedra primeiro e a seguir o escuro, o meu tio

- Continuas a saber fazer oitos?

e não existe um só pilar de granito a impedir-me de partir. (SRV, p. 114).
} 
Aqui chegamos, enfim, à proposição essencial que o presente texto procura alcançar e afirmar: assim como o poema de Camões funda-se no tema da viagem para representar a figura do indivíduo exilado, que, forçado a viver longe de Sião, considerará sempre Babilónia um não-lugar e será sempre diante desta cidade um estrangeiro, o protagonista de Sôbolos rios que vão é igualmente um homem em exílio; e, se sua viagem não é geográfica, há, ainda assim, a oposição entre dois locais de moradia diferentes (casa/hospital) e as sensações de tristeza e não-pertencimento decorrentes da estadia estrangeira.

Não se pode deixar de pensar na posição do doente como exilado sem considerar os variados aspectos que tal concepção implica. O protagonista de Sôbolos rios que vão está exilado de sua saúde, ao conviver com um tumor/ouriço crescente e inapelável, que lhe ameaça dominar a totalidade dos órgãos pouco a pouco. Está exilado também de sua rotina cotidiana, seja esta qual for, e contido no confinamento padronizado e impessoal dos quartos hospitalares. Para tornar familiar o cenário, a personagem se cerca de figuras familiares - não visitantes reais, mas personificações imaginárias de pessoas que foram de seu convívio cotidiano durante a infância: "a avó que morreu há tantos anos ali viva com ele, o avô defunto há mais tempo a ler o jornal com o seu aparelho de surdo" (SRV, p. 7). 0 fato de essas pessoas serem já falecidas remonta, naturalmente, à ideia de uma comunhão receptiva, com os parentes a esperarem a entrada de mais um membro da família no mundo além-vida; mas, para além dos delírios ou das possíveis interpretações "sobrenaturais", nos atemos simplesmente ao fato de que esses peculiares visitantes representam um elo possível com o passado desejado, trazendo Sião para perto daquele que, devido à enfermidade, ocupava Babilónia.

Sião, esse "tempo passado" presente no romance em questão, residirá justamente na inocência e na puerilidade da infância. 0 narrador recuperará, nesse ínterim, imagens como a outrora citada, dos avós, mescladas a reminiscências variadas, tais como a casa por ele ocupada na infância e a vila na qual a mesma se inseria, além de um juvenil amor platônico por uma menina que ignorava suas cartas e a descoberta de conceitos novos, como na divertida passagem em que o menino tenta desvendar o significado do termo "luxúria". A memória, portanto, assim como foi para o eu-lírico de Camões (permitindo à pena que não se cansasse quando o assunto se voltava para a terra agora distante), 
funcionará, para o protagonista, como sustentação em seu exílio involuntário. 0 retorno à noção da casa não é fortuito, como bem esclarece Ecléa Bosi:

[a casa materna] nem sempre é a primeira casa que se conheceu, mas é aquela em que vivemos os momentos mais importantes da infância. Ela é o centro geométrico do mundo, a cidade cresce a partir dela, em todas as direções. Fixamos a casa com as dimensões que ela teve para nós e causa espanto a redução que sofre quando vamos revê-la com os olhos de adulto. Para enxergar as coisas nas suas antigas proporções, como posso tornar-me de novo criança? (BOSI, 1997, p. 435).

Como tornar-se criança novamente seria impossível, cabe ao narrador recuperar passagens de sua infância por intermédio do discurso memorialístico direcionado à primeira década de vida. E aqui, mais uma vez, o recorte temporal que enquadra a Sião do romance contemporâneo não é por acaso. Sinalizamos, aqui, a proximidade entre a criança e o convalescente, apontada por Charles Baudelaire em trecho que abaixo reproduzimos:

Ora, a convalescença é como uma volta à infância. 0 convalescente goza do mais alto grau, como a criança, da faculdade de se interessar vivamente pelas coisas, mesmo pelas mais triviais em aparência. Voltemos, se for possível, por um esforço retrospectivo da imaginação, às nossas mais jovens e matinais impressões, e reconheceremos que tinham um parentesco singular com as impressões, coloridas de forma tão viva, que recebemos mais tarde após uma doença física, contanto que essa doença tenha deixado intactas as nossas faculdades espirituais. (BAUDELAIRE, 1993, p. 223).

As "jovens impressões" envolvem, além de fatos e situações, figuras, lugares e objetos que caracterizam certo tempo e ajudam na cristalização da Sião recordada, como, por exemplo, a passagem dos comboios: "o correio, o mercadorias, o rápido, aqueles que furavam a noite feitos de sombra e janelas, o relógio da estação que se atrasava sempre" (SRV, p. 65). Novamente lendo Bosi, sabemos que "mais que um sentimento estético ou de utilidade, os objetos nos dão um assentimento à nossa posição no mundo, à nossa identidade" (1997, p. 441). Por intermédio da memorização deste e de outros objetos, é possível situar pessoas e coisas na dicção memorialística.

Na leitura intertextual entre uma obra e outra, a fim de subsidiar a interpretação que no momento trazemos, também achamos pertinente tecer, aqui, algumas considerações, a título de sugestão, entre título e texto. Primeiro, o poder semântico da palavra rios, aliada ao verbo que indica passagem (vão), sugere uma contemplação da 
passagem do tempo, processo certamente similar ao que a personagem efetua, contemplando, de seu leito de hospital, todos os acontecimentos que lhe moldaram a vida. Se, no salmo bíblico e no poema camoniano, há a visão literal do rio, e, a partir deste, é efetuado um esforço memorialístico em evocação à antiga terra, no romance antuniano o rio é desde o princípio metafórico; simboliza a vivência de uma personagem que, no possível término de sua existência, avalia-a. Por outro lado, porém, há um rio explícito no romance: o rio Mondego, à beira do qual o protagonista, quando jovem, se sentava - e aqui a proximidade e o jogo tornam-se ainda mais particulares e complexos, se pensarmos na quantidade de vezes que a palavra "rio", bem como outras de seu campo semântico, ganha as páginas do volume a partir da primeira ocorrência, logo no início da obra: "apetecia-lhe regressar à nascente do Mondego, um fiozito entre penedos quase no alto da serra e não achou o fiozito, lembrava-se de musgos e musgo algum no hospital" (SRV, p. 11 - 12). Este exilado da obra de António Lobo Antunes não está sobre os rios: ao contrário, para o rio da infância deseja voltar; ou ainda, para ele, "bastava a certeza de chegar à foz" (SRV, p. 88).

No decorrer do processo de avaliação e rememoração da própria vivência, a personagem/persona adota métodos frequentes na dicção autoral, tais como a evocação da infância - quando ainda era Antoninho, e não o senhor Antunes de hoje -, e o paralelismo entre passado e presente por meio de um elemento conector similar às duas porções de tempo - há, por exemplo, no romance, a analogia entre o ouriço visualizado quando criança e o tumor encontrado na maturidade: "ouriço de um castanheiro dantes à entrada do quintal e hoje no interior de si a que o médico chamava cancro aumentando em silêncio" (SRV, p. 9). Será, inclusive, a recuperação do passado infantil o que protegerá a personagem de sua morte iminente, criando, de certa forma, uma redoma protetora que a afasta do abandono da própria vida. Ana Paula Arnaut menciona que

O que parece aliviar a dor, então, repetimos, não é a crença religiosa mas a memória do mundo sensível do passado. A pacificação é procurada não na verticalidade do divino mas na horizontalidade do humano outrora criança e agora homem. Se, em Camões, as memórias recuperadas contribuem para o ensombramento do seu mundo interior, em António Lobo Antunes, pelo contrário, elas parecem ser, apesar de algumas notas dissonantes, aquilo que o consola e tranquiliza. Por isso traz a infância para o hospital, refugiando-se nela e no interior da música que nela ouve, como se, desse modo, a morte não o apanhasse. (ARNAUT, 2008, p. 390). 
No texto, a infância é o tempo passado, equivalente a Sião, enquanto a realidade hospitalar atual é Babilônia, o espaço do desterro. Vê-se, portanto, que, assim como o texto de Camões pauta-se em uma dicotomia entre passado e presente geograficamente demarcados e representados por Sião e Babilônia -, o romance antuniano repousa sobre o constante jogo entre ontem e hoje, sempre superpostos e marcados por adjetivos próprios. Tempo anterior e tempo presente caminham juntos a ponto de, em determinados momentos, a criança que a personagem foi e o adulto em que se tornou fundirem-se:

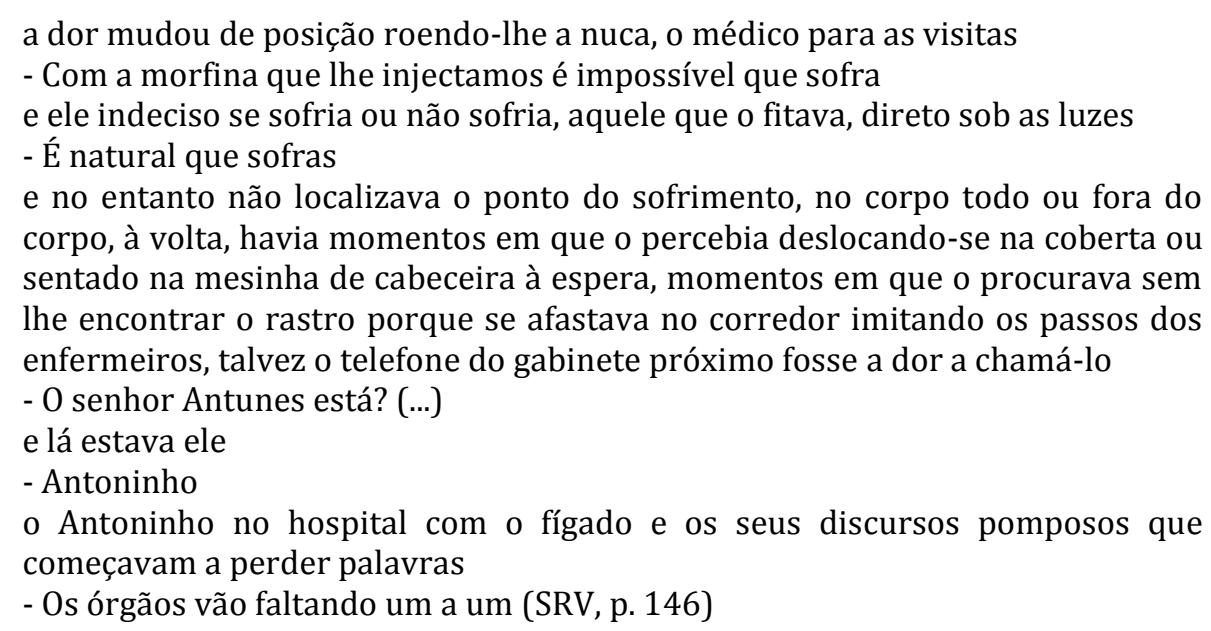

Parece sugestivo, aqui, recordarmo-nos das palavras de Maurice Blanchot: "escreve-se para salvar a escrita, para salvar sua vida pela escrita, para salvar seu pequeno eu (as desforras que se tiram dos outros, as maldades que se destilam) ou para salvar seu grande eu, dando-lhe um pouco de ar" (2005, p. 274). É consenso entre os estudiosos do autor o fato de que suas primeiras obras - Memória de elefante, Os cus de Judas e Conhecimento do inferno, respectivamente - guardam explícitos traços autobiográficos, remetendo à experiência do indivíduo Lobo Antunes enquanto médico do Exército português situado em Angola por vinte e sete meses, durante a Guerra Colonial, e depois como psiquiatra do Hospital Miguel Bombarda, em Lisboa; em textos posteriores, ocorreria não só uma ampliação temática, mas também um refinamento de técnicas narrativas, com a consolidação de certo estilo autoral. Entretanto, um retorno à proximidade autor/obra parece esboçado nas páginas semidiarísticas do romance em questão. Seria o caso? 
Certamente, um ensaio que pretendesse discriminar até que ponto Sôbolos rios que vão é um texto estritamente autobiográfico precisaria de muito mais páginas e tempo do que o que aqui dispomos. Entretanto, desejando brevemente ensejar tópicos de discussão a respeito, pensamos que, ao redigir, António Lobo Antunes concorre duplamente para a veracidade das palavras de Blanchot. 0 pequeno eu é salvo, tanto no sentido inferido pelo francês, que seria o da preservação de uma certa interioridade, quanto no contexto do romance, uma vez que a criança recordada permanece intacta e inesquecível por meio da memória. Da mesma forma, o grande eu se salva: a este senhor Antunes adulto, o relato memorialístico processado nas páginas do romance foi fundamental para a manutenção da vida, ainda que oscilante - e ousamos crer que para o indivíduo António Lobo Antunes, pessoa física, ficcionista que se encerrou em suas próprias páginas, o ato de escrever também foi determinante - tábua de salvação para a vivência. Nesse sentido, é simbólico o fato de, curiosamente, o livro se iniciar na data da primavera boreal, 21 de março - como a sugerir um renascimento possível a partir do leito de morte, e tal como aconteceu com o autor da obra, recuperado de sua enfermidade. Entretanto, também não desejamos esquecer a lição do Blanchot, ao afirmar, mais adiante no mesmo texto, que

Parece que devem permanecer incomunicáveis a experiência própria da obra, a visão pela qual começa, a "espécie de desvario" que provoca, e as relações insólitas que estabelece entre o homem que podemos encontrar no dia-a-dia e que, precisamente, escreve o diário de si mesmo, e aquele ser que vemos alçarse por detrás de cada grande obra, para escrevê-la. (2005, p. 276)

Indubitavelmente, a ficção de António Lobo Antunes sugere o desvario da e pela escrita, atingindo o âmago do leitor e, ao convalescer, convocando-o à convalescença. Por detrás de um senhor Antunes representado, simulado, e transposto para as páginas do romance, haverá sempre o ficcionista, a engendrar as malhas de seu texto com destreza, e a trazer-nos, em Sôbolos rios que vão, temas que são humanos, sobretudo: doença, envelhecimento, solidão, desterro, contraposição entre antes e agora, infância, saudade.

\section{Referências}

ANTUNES, António Lobo. As naus. Lisboa: Dom Quixote, 1988. . Ontem não te vi em Babilónia. Lisboa: Dom Quixote, 2006. 
. Que cavalos são aqueles que fazem sombra no mar? Rio de Janeiro: Alfaguara, 2011. Que farei quando tudo arde? Lisboa: Dom Quixote, 2008.

. Sôbolos rios que vão. Rio de Janeiro: Alfaguara, 2010.

. Não é meia-noite quem quer. Lisboa: Dom Quixote, 2012.

ARNAUT, Ana Paula. Entrevistas com António Lobo Antunes 1979 - 2007: confissões do trapeiro. Lisboa: Almedina, 2008.

. Introdução: dos trapos e do trapeiro. In: Entrevistas com António Lobo Antunes 1979 - 2007: confissões do trapeiro. Lisboa: Almedina, 2008.

. Sôbolos rios que vão de António Lobo Antunes: quando as semelhanças não podem ser coincidências. In: MARTINS, José Cândido e SILVA, João Amadeu (Org.). Pensar a literatura no século XXI. Braga: Faculdade de Filosofia / Universidade Católica Portuguesa, 2011, p. 385-394.

BAUDELAIRE, Charles. 0 pintor da vida moderna. In: Obras estéticas: filosofia da imaginação criadora. Petrópolis: Vozes, 1993.

BERARDINELLI, Cleonice. Estudos camonianos. Rio de Janeiro: Nova Fronteira, 2000.

BLANCHOT, Maurice. 0 diário íntimo e a narrativa. In: O livro por vir. Trad. de Leyla Perrone-Moisés. São Paulo: Martins Fontes, 2005.

BOSI, Ecléa. Memória e sociedade. São Paulo: Companhia das Letras, 1997.

CAMÕES, Luís de. Poesia lírica. Lisboa: Biblioteca Ulisseia de autores portugueses, 2002.

MARAVALL, José António. A cultura do barroco: análise de uma estrutura histórica. Trad. de Silvana Garcia. São Paulo: EDUSP, 1997.

PESSOA, Fernando. O guardador de rebanhos e outros poemas. São Paulo: Cultrix, s.d.

SARAIVA, António José; LOPES, Oscar. História da literatura portuguesa. Porto: Editora Porto, 1950.

Recebido em junho de 2014.

Aceito em outubro de 2014.

i Todas as citações que forem porventuras feitas, deste ponto em diante, a partir do romance Sôbolos rios que vão, principal objeto de estudo do artigo em questão, serão precedidas da sigla SRV, após a qual virá o número da(s) página(s) correspondente(s). 